\title{
MEMÓRIA VIVA
}

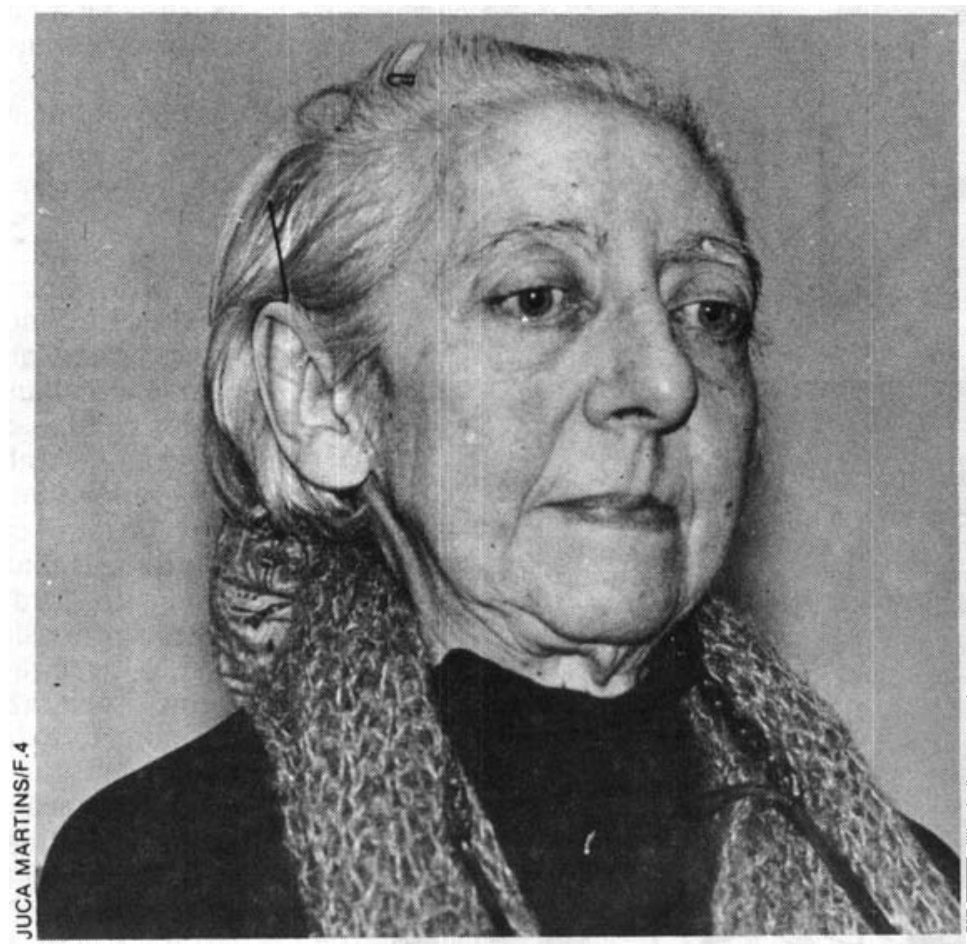

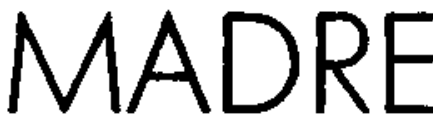

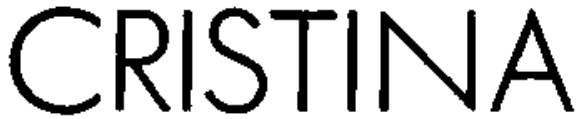

Era uma tarde de quinta-feira, de um feriado prolongado, portanto, um dia sem nenhum movimento maior. $O$ grande prédio do Instituto Sedes Sapientiae, no bairro paulistano de Perdizes, estava silencioso.

Nesse mesmo instante, a cidade de Santo André, na região do $A B C$ paulista, vivia momentos de tensão e violência. $A$ Polícia Militar invadia a fábrica da

Villares e espancava operários ali reunidos em assembléia pacifica por melhores salários.

Alguém, pelo telefone, dá um quadro da situação: muitos feridos, surpresa e pânico, um operário em estado grave na UTI.

EM ritmo lento, porém firme $e$ decidido, ela desliga o telefone, procura a sua agenda e, com alguma dificuldade para ler (está com perda parcial da visão) começa os telefonemas à procura do governador Franco Montoro, do Secretário da Segurança Pública de São
Paulo e de José Carlos Dias, Secretário da Justiça. Exige providências imediatas diante de um ato tão arbitrário e de afronta aos Direitos Humanos. Apesar da total indignação, sua voz soa calma e límpida.

E Madre Cristina Sodré Dória, 68 anos, paulista de Jaboticabal, psicóloga e professora, 12 livros publicados, fundadora e diretora do Instituto Sedes Sapientiae - "esse é o nosso papel: intervir, participar, influir, trabalhar para a conquista de uma sociedade livre, justa e igualitária".

Conhecida no meio universitário não só pelos seus 35 anos de magistério, mas também por sua constante atuação política em defesa dos Direitos Humanos, Madre Cristina é parte da própria história da Psicologia no Brasil.

Nessa entrevista ela fala de suas experiências, sua opção política, suas expectativas e alerta os psicólogos para assumirem um papel de transformadores da atual realidade brasileira. 
Vocês estão angustiados? Eu não tenho angústia por vocês. Tenho angústia por aqueles que nem angústia têm.

Há sete anos Madre Cristina é a diretora do Instituto Sedes Sapientiae, desde que ele se desligou da Pontificia Universidade Católica de São Paulo (PUC), em 1975, para ressurgir com uma nova proposta - ser um espaço aberto aos que querem se comprometer com a busca de um projeto alternativo para a sociedade brasileira.

De que maneira o Sedes está construin. do esse projeto alternativo?

Temos 20 cursos em nível de pósgraduação, nas áreas de Psicologia, Psicoterapia, Filosofia e Educaçāo Popular e desenvolvemos um modelo próprio de trabalhar, como está definido em nossa "Carta de Princípios". Procuramos pautar nossas atividades pelas linhas fundamentais que consagram o homem como principio, a realidade social brasileira como campo de trabatho, o exercício de defesa dos direitos humanos como método e a libertação como fim.

Abrimos aqui um espaço, para qualquer pessoa que queira fazer um trabatho de busca. Onde possamos discutir um projeto de transformação da realidade, para encontrar um caminho de uma sociedade socialista.

Não queremos modelos importados da Uniāo Sovietica, China ou Albânia, e sim um modelo brasileiro. Mas o que é esse modelo brasileiro? Temos uma interrogação, mas ainda não temos a resposta.

\section{Como essa proposta acontece na práti-} ca?

Existe aqui um grupo interprofissional de Educação Popular. Eles estão trabalhando junto a Sindicatos, oposição sindical e assessorando grupos em todo o Brasil, inclusive na Nicarágua e El Salvador. Esse é o tipo de trabalho que o Sedes se propôs.

Com os cursos de Psicologia que criamos a proposta é realmente encontrar a forma da Psicologia ser um instrumento a serviço do processo de transformação da sociedade.
Mas, a passagem da teoria para a prática ainda é uma angústia. Muitos sentem que não estāo encontrando o projeto alternativo que buscavam. Então eu digo sempre: Vocês estão angustiados? Eu não tenho angústia por vocês. Tenho angústia por aqueles que nem angústia têm.

Não importa se esse projeto aparecer daqui a 100 ou 1000 anos, o que importa é começar.

Quais são as dificuldades?

A primeira grande dificuldade è o pessoal fazer uma opção prática, o que implica numa mudança de vida. Por exemplo, esse pessoal do Centro de Educação. São profíssionais de altíssimo nível, que poderiam estar ganhando muito dinheiro em consultórios particulares, no entanto, estão aqui ganhando $o$ suficiente para a sobrevivềncia. Isso é uma opção de vida, se comprometer nāo de maneira festiva, mas efetiva, com uma pratica de transformação.

O segundo grande obstáculo é que as pessoas, querendo se comprometer, não sabem como fazêtlo. Porque os modelos teóricos de Psicologia são elitistas voltados para consultórios. Então, há toda uma busca, um trabalho a ser feito. Essa é uma de nossas preocupaçōes - ter um instrumental capaz de adaptar.

Não queremos resultar em um nivelamento por baixo - psicoterapia para pobre e psicoterapia para rico. Queremos chegar ao resultado de uma Psicologia a mais eficiente possivel, aplicável tanto a ricos como a pobres. Isso porque sonhamos, como devemos sonhar, com uma sociedade sem classes, não importa para quando. Temos que acreditar no hoje, trabalhar e investir tudo na certeza que as coisas vão acontecer amanhã. A gente trabalha nessa perpectiva.

\section{O que a Madre faz naquela casinha? Ela trata de loucos?}

Como foi o seu processo de opção profissional?

Escolhi a carreira de psicóloga mesmo antes de saber que o psicólogo existia. Desde muito criança imaginava: quando crescer quero estudar o que se passa dentro das cabeças das pessoas. Tinha vontade de cortar a cabeça do médico da nossa família para saber tu. do que existia lá dentro. Com alívio, descobri mais tarde que com a Psicologia poderia estudar o ser humano e seus comportamentos, sem chegar ao extremo de cortar cabecas.

E quanto a ser psicóloga-professora nunca tive dúvidas. Para mim a única maneira de aprender é ensinar.

O problema, na época, era que a Psicologia só existia nas Escolas Normais e o que se aprendia era muito pouco. Havia também o antigo Sedes com Psicologia nos cursos de Pedagogia e Filosofia.

Me matrículei na Escola Normal Caetano de Campos e no Sedes, em 1937. Comecei a ter una base de Psicologia bastante rica, e ao mesmo tempo com duas visðes diferentes - a européia e a americana, através de duas professoras convidadas do Sedes.

Em 1940, quando me formei, tentei transformar o Curso de Pedagogia em Curso de Psicologia. A gente esvaziava o curriculo mínimo e colocava todas as cadeiras de Psicologia - da personalidade, social, diferencial, testes, diagnósticos. Começamos a criar realmente um curso de Psicologia, e nesse mesmo ano já tínhamos a primeira Clínica Psicológica do Sedes.

E como eram as atividades nessa clínica?

O próprio nome - Clinica Psicológica foi um escândalo na época, ninguém sabia o que era. Naturalmente diziamos que năo era para atender nem para prestar serviços, era um local para aprendermos. Então convidávamos amigos, parentes e faziamos experiências. Tinhamos parte do diagnóstico, orientação de pais e professores, orientação vocacional e trabalho corretivo de aprendizagem escolar.

Eu lia Freud durante 14 horas por dia, porque não tinha onde aprender. Os alunos da clínica pressionavam-me para que transformássemos aquilo num curso de Psicologia Clínica. Eu nåo aceitava, não queria ser charlatã , nâo me via em condição de ser professora. Até que a coisa amadureceu. Precisei viajar e estudar na Europa e Estados Unidos para me sentir menos insegura.

O primeiro curso foi, então, proposto assim: vamos ser honestos, reunir o pessoal que está interessado e ser ao mesmo tempo aluno e professor. Dessa forma montamos, em 1953, o curso de 
Psicologia Clínica, com duração de 3 anos, para os formados em Pedagogia ou Filosofia.

Havia problemas de confronto com outras áreas?

O que havia era uma total confusão, um grande desconhecimento do que era a Psicologia. Não se podia falar em psicoterapia, tínhamos a pressắo dos médicos. Para regularizar a profíssão de psicólogo tivemos que criar o termo "problemas de ajustamento".

Foi a partir de 1955, que a Psicologia começou a ficar na moda. A ciência era vista como algo ligado à bola de cristal, à magia, mas tudo isso era válido.

Comecei, entao, a dar cursos, a ser convidada por escolas de todo o País para palestras e conferéncias, para explicar o que era Psicologia. A divulgação começou a ser intensa. Nas palestras o pessoal sugava a gente. Sentiamos o interesse pela coisa nova e que respondia a uma necessidade. Naturalmente, havia sempre aquela forma mágica, mistica - o que eu tenho? O que eu sou? Essa imagem era muito frequiente.

Uma idéia que estava também ligada à Psicologia era a idéia de louco. As pessoas perguntavam, se referindo à nossa Clínica Psicológica: o que a madre faz naquela casinha? Ela trata de loucos? As pessoas tinham vergonha de ter que fazer psicoterapia. Em pouco tempo a mudança foi tão grande, que fica dificil avaliar como era e como é.

Como o curso foi sendo estruturado, enquanto forma de ensino?

Havia grande carência de professores. Os primeiros se formavam como autodidatas e vinham seguir cursos de fim de semana e fazer supervisőes.

Naquela ocasião se prestava pouca atenção ao currículo. $O$ que procuravase era descaracterizar os nomes, por exemplo, Psicoterapia, nåo aparecia nunca para não entrar em conflito com a terminologia médica.

No curso de três anos dávamos uma visão das áreas de clínica, educacional e do trabalho. Mas, era impossível aprender e aprofundar em todas, principalmente nos estágios práticos.

Comecei a perceber que essa Psicologia ensinada estava mais voltada para problemas pessoais, no máximo para uma micro sociedade, no caso a familia.
Isso foi me preocupando muito, porque para mim o grande problema eram as injustiças, as diferenças das classes sociais. Então, minha vontade era descobrir como o psicólogo poderia contribuir, dentro de sua profissāo, para transformar a sociedade. Não sabíamos como a Psicologia poderia ajudar, mas sabíamos que podiamos formar psicólogos com preocupações políticas, que o levassem a atuar.

Vimos que era impossivel fazer isso dentro do Sedes. Lá dentro havia desde a TFP - Tradição, Família e Propriedade até a AP - Ação Popular, ficávamos nos degladiando o tempo todo. Aí então, o Sedes se integrou à PUC, onde ficamos até 1975.

Durante esse período ocorreram grandes transformaçōes dentro da sociedade. Minha Congregação, Cônegas de Santo Agostinho, depois do Vaticano II, do Encontro de Puebla e do surgimento da Teologia da Libertação deu uma guinada de 180 graus e fez opçăo pelos pobres. Resolvemos trabalhar realmente pela transformaçăo da sociedade, eni busca de um mundo mais justo.

Com a venda de nosso Colégio, destinado à elite, construímos o prédio desse atual Sedes, com a idéia de um projeto alternativo e nos desligamos da PUC.

Qual seria a atuação psicológica adequada para o momento atual?

\section{Nossa preocupação \\ é como o psicólogo \\ pode intervir \\ no processo de \\ transformação \\ da sociedade}

Queremos através de nossa Clínica de Atendimento dar um alto nivel de terapia e gratuito às pessoas menos favorecidas. Acreditamos que quem fará a revolução será o povo. Queremos dar a ele condiçðes emocionais capazes de suportar o processo de uma revoluçã̃o social.

Ainda temos muitas interrogações mas, graças a Deus, há grupos interessados em procurar essas respostas. Hoje nosso grupo de Psicanálise, através de um convêncio com a Coordenadoria de Saúde Mental do Estado,está dando supervisão nos Postos de Saúde da periferia.
Nossa consideração é que se existem pobres e ricos isso é fruto de uma sociedade injusta. Como você pode contribuir para que um dia ela seja uma sociedade sem classes, sem opressåo, sem injustiças? Acreditamos nisso e criamos o Sedes para isso

Que influência tem o momento político nesse processo?

Eu acho que 20 anos de repressão se por um lado causaram grandes estragos e recuo, por outro lado aceleraram o processo de conscientização.

Encontro centenas de jovens que vêm me perguntar o que fazer, em que movimento entrar. A juventude está muito mais comprometida com os processos históricos do que no meu tempo.

Há uma participação maior - a classe operária através dos sindicatos e da CUT - Central Unica dos Trabalhadores $e$ a classe média buscando formas de atuação, como ficou evidenciado na campanha por eleiçðes diretas. As perspectivas são boas, todos sentem que a sociedade não pode continuar assim.

O cidadäo brasileiro quer descobrir o seu caminho, como descobriu o cidadão nicaraguense. Somoza morreu, mas está aí o Somoza II, que é o Reagan, atrapalhando muitos projetos.

Quais são as perspectivas para o psicólogo?

O trabalhador da saúde mental é o psicólogo, existe um campo para ele, importantíssimo, fundamental, que o povo está descobrinhdo e por ele pedindo. Então o campo está aí, o psicólogo tem que descobrir o seu caminho.

Pense, procure e se engaje em todos os movimentos que estiverem abertos. Fique alerta, não fique fechado dentro da sua Psicologia, do seu consultório, achando que isso é o suficiente. Fique sempre angustiado, e não leve essa angústia ao seu terapeuta. Sustente-a e busque práticas para a descoberta de um caminho.

Não fique tranquílo, não desanime porque năo existe um projeto ou, não sei o que fazer, não sei onde trabalhar. Histótia é História, o que importa é o que eu vou fazer hoje.

A maneira de passar dessa visão teórica para uma prática consequente exige um caminhar. Mas não faz mal, eu tenho muita esperança.

Hoje a gente está vendo a História se construir e eu nåo gostaria de ter vivido em outra época. 


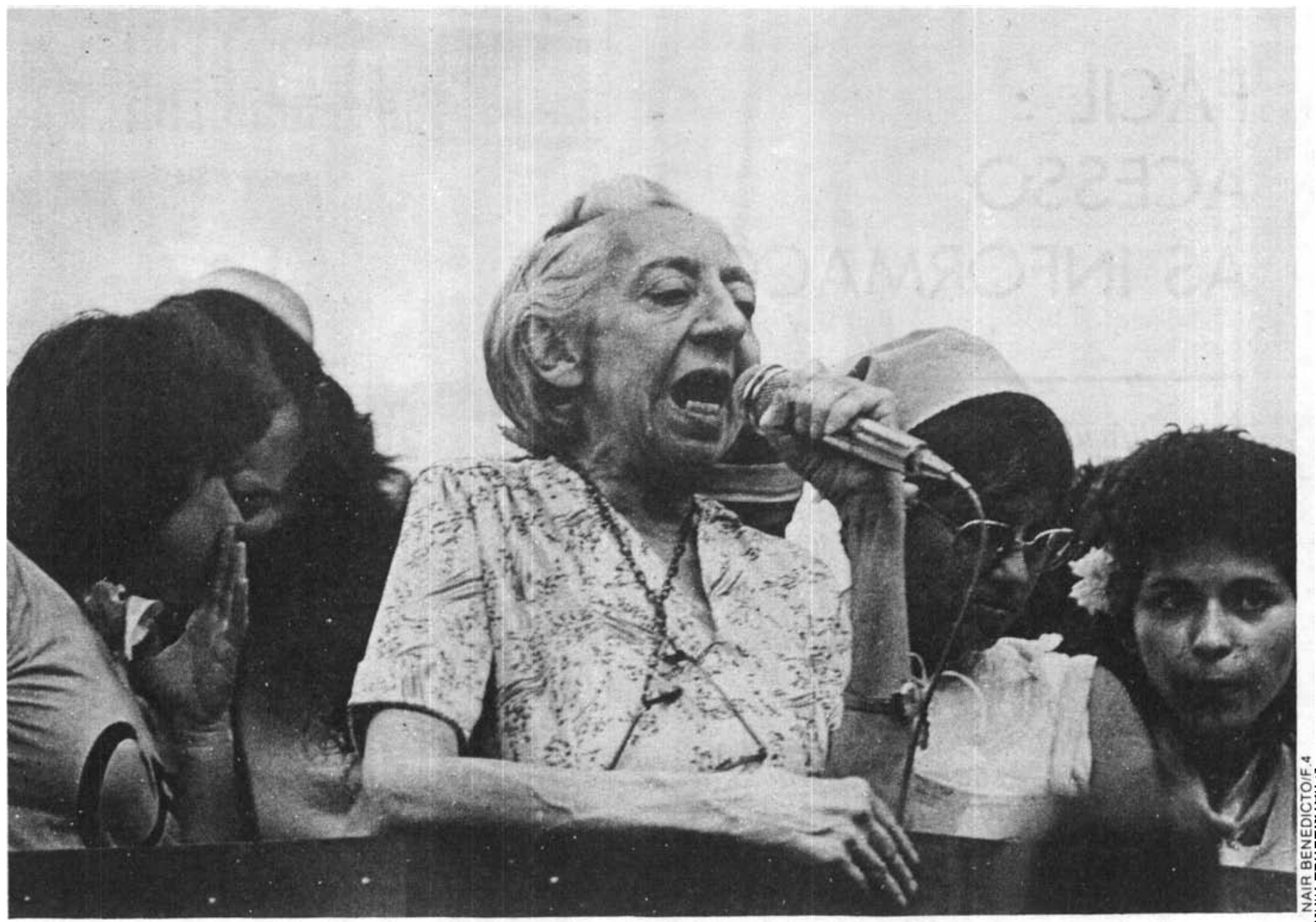

\section{LIVROS E ARTIGOS PUBLICADOS}

Consideraçōes sobre o significado da angústia

Rev. de Psic. Normal e Patológica - 1955

Psicopatologia

Editora Sedes Sapientiae - 1958

Caractertsticas masculinas e femininas da personalidade

Revista da PUC de São Paulo - 1959

Critérios para uma definicão normal Rev. de Psic. Normal e Patológica - 1959

Formação do Psicologo e Regulamentação da Profíssäo

Bol. Soc. Psicólogos de Sáo Paulo,

n.' $18,19,20-1960$

\section{Psicologia Educacional}

Edit. Faculdade Ijui, RS - 1961

Posição da Orientação Educacional da
Escola Secundaria

Ministério da Educaçâo - 1961

Amor, Sexo e Seguranca

Edit. Faculdade liui, RS - 1967

\section{Reforma Universitária}

Comissāo Parlamentar de Inquérito -

Bol. "Diário do Congresso Nacional",

suplemento 26 - de 29/11/1967

Personalidade e Familia

An. Sedes Sapientiae - 1968

Psicologia Cientifica Geral

Editora Agir, $12^{\circ}$ edição -1982

\section{Educando nossos fithos}

Editora Sedes Sapientiae, 8. ediçâo - 1983

Psicologia do Ajustamento Neurotico

Editora Vozes, 5. ediçäo - 1983 